\title{
Germination and Seedling Growth of Indian Mustard Exposed to Cadmium and Chromium
}

\author{
Luca Marchiol*, Silvia Assolari, Guido Fellet, Giuseppe Zerbi \\ Dipartimento di Scienze Agrarie e Ambientali, Università di Udine \\ Via delle Scienze 208, 33100 Udine, Italy
}

Received: 11 December 2003. Accepted: 15 November 2004

\begin{abstract}
To make phytoremediation a technically viable option for large-scale applications we need plants that are able to guarantee high biomass yield as well as high accumulation of heavy metals in their aerial parts. The aim of this investigation was to study the performance of aquacultured plants of Indian mustard in the presence of different concentrations of cadmium and chromium since seed germination. The effects on germination and growth of seedlings of Indian mustard (Brassica juncea L. Czern) cv. WNFP, Varuna and Barton, were investigated in/under hydroponic conditions during a 4-week experiment. Cadmium and chromium were provided since germination as cadmium nitrate $\mathrm{Cd}\left(\mathrm{NO}_{3}\right)_{2}$ and chromium bichromate $\mathrm{K}_{2} \mathrm{Cr}_{2} \mathrm{O}_{7}(0.5,1$ and $1.5 \mathrm{M})$. Plant biomass growth measured at the end of the experiments varied with the different metal concentrations in the nutrient solution and the accumulation of the elements in the plant fractions differed significantly among/between cultivars. Ability in the uptake of metals and their mobilization and storage in the aerial plant biomass, expressed by the bioconcentration factor (BCF) and translocation factor (TF), respectively, are the most important traits of plants with phytoextraction potential. Brassica juncea was confirmed as being a highly tolerant species, but poor metal translocation values were registered, therefore the high amount of $\mathrm{Cd}$ and $\mathrm{Cr}$ concentrated in the root systems did not migrate to the aerial, harvestable, part of the plant.
\end{abstract}

Key-words: Brassica juncea, heavy metals, phytoremediation, soil pollution.

\section{Introduction}

Much effort and several methods have been directed to the clean up of heavy metal contamination of soils. One technique, known as phytoremediation, uses specially selected and engineered metal accumulating plants for environmental clean-up. This has advantages such as low costs, minimal environmental disturbance, applicability to a wide range of pollutants (organic compounds, heavy metals, radionuclides) and public acceptance. The disadvantages of this option are mainly that (a) phytoremediation is effective only in the case of shallow soil pollution and (b) it takes longer than other methods (Mulligan et al., 2001).

So far, researchers have gained significant results in the understanding of molecular mechanisms of metal uptake and the physiology of metal tolerance by hyperaccumulator species
(Clemens et al., 2002; Kochian et al., 2002).

To make phytoremediation a technically viable option for large-scale applications we need plants that can guarantee high biomass yield as well as high heavy metal accumulation in their aerial parts.

Unfortunately, hyperaccumulator species are not suitable due to their small biomass and slow growth. As an alternative the use of high biomass species has been suggested: Indian mustard (Brassica juncea L. Czern), is one of these. Although it is not a hyperaccumulator, it has demonstrated high tolerance to several heavy metals (Ebbs and Kochian, 1998; Hammer and Keller, 2002; Jiang et al., 2003). Dushenkov et al. (1997) reported B. juncea as being particularly effective in sorbing divalent cations of toxic metals from soil solution and Salt et al. (1997) demonstrated that Indian mustard has a greater 
ability to accumulate $\mathrm{Cd}$ from hydroponic solution into the above-ground biomass than other crops.

Evidence of $B$. juncea $\mathrm{Cr}$ tolerance came from experiments by Shahandeh and Hossner (2000 a, b), who screened a series of crops and observed the effects of organic acids for enhancing $\mathrm{Cr}$ uptake from polluted soil. More recently Mei et al. (2002) provided data on $\mathrm{Cr}^{3+}$ and $\mathrm{Cr}^{6+}$ tolerance and uptake of Indian mustard grown in nutrient solution.

Future application of phytoremediation projects require theoretical knowledge of the physiological and molecular basis of metal tolerance, but also require practical experience around the behavior of plants in the most common situation of man-polluted soils, that is the presence of several toxic elements and/or organic pollutants.

Anyway, an obvious prerequisite of plants is that they resist adverse conditions since/from the early steps of the growing cycle: germination and seedling growth. Some aspects of appropriate planting practices in metal-phytoextraction projects have been discussed by $\mathrm{Li}$ et al. (2003).

The aim of this investigation was to study the performances of aquacultured plants of Indian mustard in the presence of different concentrations of cadmium and chromium since/from seed germination.

\section{Materials and methods}

As the aim of the study was to grow plants in the presence of cadmium and chromium, preliminary tests were done to determine the nontoxic levels of these elements. $\mathrm{Cd}$ and $\mathrm{Cr}$ concentrations were tested in the interval 100-0.05 $\mu \mathrm{M}$. At high values of metal concentration the seeds germinated but the plants showed toxicity symptoms such as purple and necrotic spots on primary leaves and they subsequently died.

The results of these tests indicated $0.5 \mu \mathrm{M}$, $1 \mu \mathrm{M}$ and $1.5 \mu \mathrm{M}$ as non-toxic concentrations of $\mathrm{Cd}$ and $\mathrm{Cr}$ for seed germination and normal seedling growth.

Seeds of Indian mustard (Brassica juncea) cv WNFP, Varuna and Barton, provided by the Brassica collection of the University of Padova (Italy), were germinated and grown for a week in containers with $4 \mathrm{~cm}$ deep sand watered with a modified Hoagland solution (Brown et al., 1995).

The Hoagland solution consisted of $0.5 \mathrm{mM}$ $\mathrm{Ca}\left(\mathrm{NO}_{3}\right)_{2}, 0.5 \mathrm{mM} \mathrm{KNO}, 2 \mu \mathrm{M}$ Fe-Na-EDTA, $20 \mu \mathrm{M} \mathrm{K} \mathrm{HPO}_{4}, 15 \mu \mathrm{M} \mathrm{KCl}, 2 \mu \mathrm{M} \mathrm{H}_{3} \mathrm{BO}_{4}, 0.2$ $\mathrm{mM} \mathrm{MgSO}{ }_{4}, 0.8 \mu \mathrm{M} \mathrm{MnCl}_{2}, 0.1 \mu \mathrm{M} \mathrm{CuSO}_{4}, 0.2$ $\mu \mathrm{M} \mathrm{ZnSO}, 0.04 \mu \mathrm{M} \mathrm{K}_{2} \mathrm{MoO}_{4}$. Standard Hoagland solution was used for the controls. Solution $\mathrm{pH}$ was adjusted to 6.0 by the addition of $\mathrm{KOH}$ as necessary.

Cadmium and chromium were provided as cadmium nitrate $\mathrm{Cd}\left(\mathrm{NO}_{3}\right)_{2}$ and chromium bichromate $\mathrm{K}_{2} \mathrm{Cr}_{2} \mathrm{O}_{7}$ respectively, reaching 0.5 , 1 and $1.5 \mu \mathrm{M}$ in the nutrient solution for both elements, corresponding to $0.056,0.112$ and $0.168 \mathrm{mg} \mathrm{l}^{-1}$ for cadmium and 0.052, 0.104 and $0.156 \mathrm{mg} \mathrm{l}^{-1}$ for chromium respectively.

Four days after the beginning of the experiment plants had fully expanded primary leaves; after 7 days the seedlings were transferred to 2.51 plastic beakers containing aerated nutrient solution.

The plants were grown for $21 \mathrm{~d}$ on a laboratory bench lit by lamps giving $500 \mu \mathrm{mols} \mathrm{m}^{-2} \mathrm{~s}^{-1}$ of photosynthetically active radiation (PAR) at the plant top, with a 12:12 hours photoperiod; the pots were rotated randomly daily to equalize their light exposure; ambient temperature was maintained at $22 \pm 2^{\circ} \mathrm{C}$.

During the first week of hydroponic growth, the plants were provided with the same nutrient solution (modified Hoagland 1:10) used in the seed germination phase; in the following weeks a modified Hoagland 1:5 was used. The nutrient solutions were changed every 3 days to compensate for water lost through evaporation and plant transpiration.

At the end of the experiment, the total area of the leaves in control and treated plants was measured using a leaf area meter (LiCor-3000, LiCor). Leaves, stems and roots of five plants per treatment were collected, taking particular care with the root apparatus; fractions were fresh weighed and oven-dried $\left(105^{\circ} \mathrm{C}, 24 \mathrm{~h}\right)$ to determine their dry matter.

The plant fractions from treated and control pots, and soil samples from the same pots were subjected to microwave-assisted total digestion (US EPA, 1994). Total Cd and Cr content on the plant fractions were determined by an ICPAES (Spectro CirosCCD). 
The phytoextraction potential of the plants was estimated by calculating the bioconcentration factor $\left(\mathrm{BCF}=\mathrm{C}_{\text {aerial }} / \mathrm{C}_{\text {solution }}\right.$, where $\mathrm{C}$ represents the concentration of metal) and translocation factor $\left(\mathrm{Tf}=\left(\mathrm{C}_{\text {aerial }} / \mathrm{C}_{\text {root }}\right) \times 100\right)$ (Mattina et al., 2003).

The trial was arranged in a randomized design with seven treatments (control, $\mathrm{Cd} 0.5 \mu \mathrm{M}$, Cd $1 \mu \mathrm{M}$, Cd $1.5 \mu \mathrm{M}$, Cr $0.5 \mu \mathrm{M}$, Cr $1 \mu \mathrm{M}$ and $\mathrm{Cr} 1.5 \mu \mathrm{M}$ ) and two pots per treatment; each treatment had 10 plants. Five plants per treatment were sampled.

Analysis of variance and the Student-Newmann-Keuls test $(\mathrm{p}<0.05)$ were used to compare treatment means. Data are presented as means with standard error. All statistics were computed using CoHort (CoHort Software, Monterey, CA).

\section{Results}

The effects of $\mathrm{Cd}$ and $\mathrm{Cr}$ on plant biomass growth measured at the end of the experiment, as expected, varied with the different concentrations of metal in the nutrient solution (Figure 1). The cultivars of Indian mustard performed differently, as confirmed by ANOVA ( $P$ $=0.012 *)$; also the interaction "treatment $\times$ cultivar" $\left(\mathrm{P}=0.014^{*}\right)$, being significant at analysis of variance, meant they reacted differently to the treatment. This was recorded for cvs WNFP and Varuna, and appeared more clearly in the case of chromium; the plants exposed to the lower $\mathrm{Cr}$ concentration suffered a reduction of total biomass ( $37 \%$ less than the controls). As suggested by Figure 1, cv. Barton showed a certain tolerance to the metals, in fact only in plants subjected to the higher treatment was a

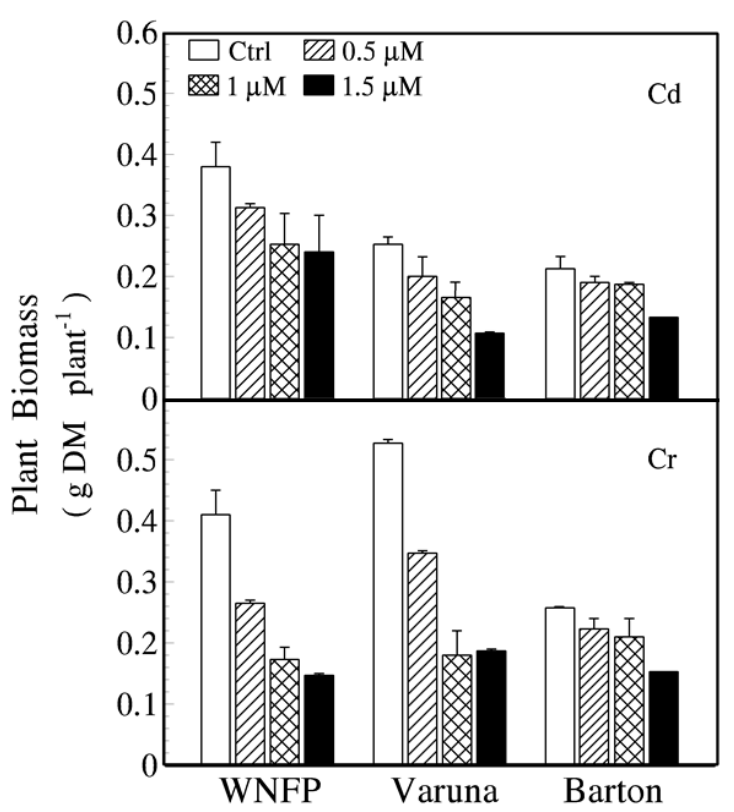

Figure 1. Plant biomass of control plants and treated plants of Brassica juncea cv WNFP, Varuna and Barton; treated plants were exposed to $0.5,1$ and $1.5 \mu \mathrm{M}$ of $\mathrm{Cd}$ and $\mathrm{Cr}$. Vertical bars represent the standard error for five replicates.

significant biomass reduction recorded. The biomass production of control plants and those subjected to the lower and intermediate treatments $(0.5$ and $1 \mu \mathrm{M}$ of $\mathrm{Cd}$ and $\mathrm{Cr}$, respectively) were more or less the same.

Table 1 reports the cadmium and chromium concentrations measured in the plant fractions by means of ICP analysis and the results of ANOVA.

The accumulation of heavy metals in the roots, stems and leaves of the three cultivars of $B$. juncea varied depending on the concentration of each element in the culture media.

Table 1. Cadmium and chromium accumulation by B. juncea cv. WNFP, Varuna and Barton.

\begin{tabular}{|c|c|c|c|c|c|c|c|c|c|c|}
\hline \multirow{2}{*}{$\begin{array}{l}\text { Treatment } \\
\text { Element } \mu\end{array}$} & & \multicolumn{3}{|c|}{ Leaves ( $\left.\mu \mathrm{g} \mathrm{g}^{-1} \mathrm{DW}\right)$} & \multicolumn{3}{|c|}{ Stems $\left(\mu \mathrm{g} \mathrm{g}^{-1} \mathrm{DW}\right)$} & \multicolumn{3}{|c|}{ Roots $\left(\mu \mathrm{g} \mathrm{g}^{-1} \mathrm{DW}\right)$} \\
\hline & $\mu \mathrm{M}$ & WNFP & Varuna & Barton & WNFP & Varuna & Barton & WNFP & Varuna & Barton \\
\hline \multirow[t]{3}{*}{$\mathrm{Cd}$} & 0.5 & $43.3 \pm 3.42 \dagger$ & $52.9 \pm 2.80$ & $34.3 \pm 1.02$ & $20.3 \pm 3.52$ & $27.0 \pm 2.55$ & $25.6 \pm 2.01$ & $150 \pm 11$ & $153 \pm 14$ & $230 \pm 42$ \\
\hline & 1 & $82.4 \pm 21.6$ & $72.3 \pm 12$ & $48.8 \pm 4.86$ & $55.1 \pm 11.8$ & $59.7 \pm 3.67$ & $31.2 \pm 5.74$ & $194 \pm 50$ & $311 \pm 176$ & $235 \pm 70$ \\
\hline & 1.50 & $52.7 \pm 12.7$ & $80.6 \pm 5.05$ & $65.2 \pm 1.88$ & $37.0 \pm 4.95$ & $71.5 \pm 10.9$ & $52.6 \pm 8.21$ & $363 \pm 102$ & $627 \pm 45$ & $393 \pm 163$ \\
\hline \multirow[t]{3}{*}{$\mathrm{Cr}$} & 0.5 & $1.80 \pm 0.07$ & $1.74 \pm 0.15$ & $0.54 \pm 0.17$ & $6.01 \pm 0.33$ & $5.68 \pm 0.90$ & $0.72 \pm 0.12$ & $303 \pm 46$ & $158 \pm 13$ & 37.8 \\
\hline & 1 & $4.57 \pm 2.09$ & $2.58 \pm 0.51$ & $4.17 \pm 0.38$ & $18.5 \pm 0.77$ & $14.1 \pm 2.23$ & $14.3 \pm 0.18$ & $851 \pm 100$ & $602 \pm 62$ & $515 \pm 17$ \\
\hline & 1.50 & $6.00 \pm 0.34$ & $6.38 \pm 0.26$ & $4.46 \pm 0.11$ & $24.6 \pm 2.49$ & $22.1 \pm 2.15$ & $19.2 \pm 1.65$ & $721 \pm 96$ & $736 \pm 56$ & $770 \pm 214$ \\
\hline \multirow[t]{3}{*}{ ANOVA } & $\mathrm{T}$ & \multicolumn{3}{|c|}{$\mathrm{P}=0.000 * * *$} & \multicolumn{3}{|c|}{$\mathrm{P}=0.000 * * *$} & \multicolumn{3}{|c|}{$\mathrm{P}=0.000 * * *$} \\
\hline & $\mathrm{Cv}$ & \multicolumn{3}{|l|}{$\mathrm{P}=0.058 \mathrm{~ns}$} & \multicolumn{3}{|c|}{$\mathrm{P}=0.007 * *$} & \multicolumn{3}{|c|}{$\mathrm{P}=0.359 \mathrm{~ns}$} \\
\hline & $\mathrm{T} \times \mathrm{Cv}$ & \multicolumn{3}{|l|}{$\mathrm{P}=0.088 \mathrm{~ns}$} & \multicolumn{3}{|c|}{$\mathrm{P}=0.027 * *$} & \multicolumn{3}{|c|}{$\mathrm{P}=0.166 \mathrm{~ns}$} \\
\hline
\end{tabular}

$\dagger$ Standard Error. 
The accumulation of the elements in the stems of the plants differed significantly among cultivars; in the case of chromium the accumulation was lower than in WNFP and Varuna.

At the end of the experiment the plants had concentrated Cd 450-3000-fold that of the concentration in the solution. As regards $\mathrm{Cr}$, in leaves, stems and roots values were 40, 160 and 6000 times higher than in the solution, respectively.

Taking the average of the cultivars, the $\mathrm{Cd}$ concentration in stems reached values 3-fold that of $\mathrm{Cr}$; on the contrary, the $\mathrm{Cr}$ concentration in roots was double that of $\mathrm{Cd}$.

Cadmium was accumulated in plants with the following distribution: roots $>$ leaves $>$ stems. This is not true for $\mathrm{Cr}$, apart from the roots. As Table 1 reports, concentrations of this element were higher in stems than in leaves.

The most important traits of plants with a potential for rhizofiltration are the ability to uptake metals, their mobilization in plant tissues and storage in the aerial plant biomass; the ability of a plant to take up and transport a toxic element to the aerial part is measured by the bioconcentration factor (BCF).

The calculated BCF is reported in Table 2, which shows significant differences in cultivar behavior ( $\mathrm{P}=0.026^{* *}$ at ANOVA).

The relationship between $\mathrm{BCF}$ and $\mathrm{Cd}$ concentration is inverse for cvs. Varuna and Barton; again, in the presence of cadmium it can be noted that cv. Barton gave the lower BCF values than the others (Table 2).

Distribution of the metals in plant tissues pointed out by the translocation factor (TF) is also reported in Table 2. At the same concentration, $\mathrm{Cr}$ was translocated less than $\mathrm{Cd}$ by plants. ANOVA gave no significant difference in the TF of the three B. juncea cultivars (Table 2).

\section{Discussion and conclusions}

This investigation studied the germination and 4-weeks growth of Indian mustard plants exposed to $\mathrm{Cd}$ and $\mathrm{Cr}$ contamination.

The concentration of the elements in the nutrient solution was not very high: this was done for different reasons. The first is that with higher concentrations, tested in preliminar tests, the seedlings showed phytotoxicity symptoms; the second one refers the fact that B. juncea is not an hyperaccumulator; finally, as stated by Baker et al. (2000), phytoextraction at present is effective only for soil "polishing" rather than for a full site decontamination.

However the $\mathrm{Cd}$ and $\mathrm{Cr}$ concentrations we chose were coherent with, and at the same magnitude as the lower values considered by Brown et al. (1995) who studied the uptake of zinc and cadmium by the metallophyte Thlaspi caerulescens. Further confirmation about the concentration values of the heavy metals in our experiment came from an experiment conducted by Salt et al. (1997) who observed the uptake of several heavy metals by five-day old seedlings of aquacultured B. juncea.

A lot of authors have reported hydroponic experiments on seedlings or adult hyperaccumulator or non-hyperaccumulator plants growing in a nutrient solution containing heavy metals, but the plants had always germinated in the absence of metals that were added during the plant growing cycle. On the other hand, the transition from an inert quiescent seed to a vital metabolizing system is a very vulnerable phase which can seriously impair the functionality of the young plant.

The results of this experiment indicate that

Table 2. Bioconcentration factor and translocation factor calculated for B. juncea cv. WNFP, Varuna and Barton.

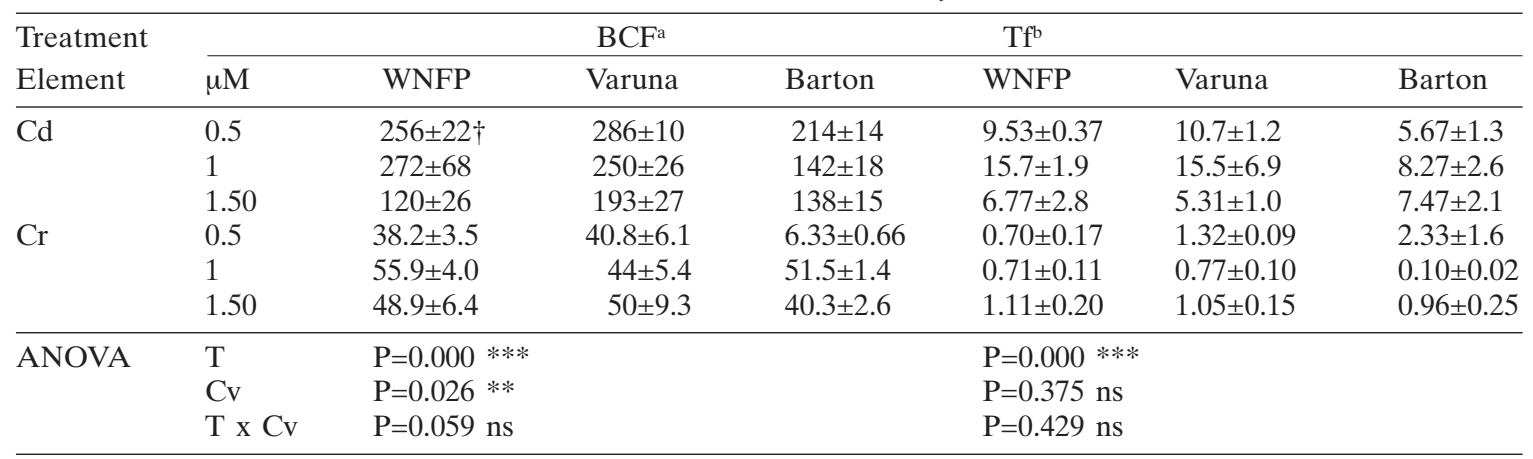

$\left.{ }^{\mathrm{a} B C F}=\mathrm{C}_{\text {aerial }} / \mathrm{C}_{\text {solution }},{ }^{\mathrm{b}} \mathrm{Tf}\left(\mathrm{C}_{\text {aerial }} / \mathrm{C}_{\text {root }}\right) \times 100\right), \dagger$ Standard Error. 
plant growth was affected by the presence of $\mathrm{Cd}$ and $\mathrm{Cr}$ : the higher the metal concentration, the less biomass produced by the cultivars.

Plants did not seem to have the same tolerance to the metals nor the same efficiency in root-shoot translocation; plants growth in the presence of $\mathrm{Cd}$ reveals a better translocation factor, even if it is unclear if the concentration of the metal affected its movement in the different cultivars.

$B$. juncea was confirmed as being a highly tolerant species, but low values of metal translocation were registered, so the high amount of $\mathrm{Cd}$ and $\mathrm{Cr}$ concentrated in the root systems did not migrate to the aerial, harvestable, plant parts.

The phytoremediation potential of a plant depends on several factors; the amount of biomass produced and the bioconcentration factor (Zhao et al., 2003) are very important. Other relevant factors that are able to determine the efficiency of phytoextraction of heavy metals are represented by the bioavailability of metals in soil and the root morphology.

Taking into account the applied aspects of phytoremediation, it must be considered that any soil clean-up obtained through plants starts with sowing and germination.

Concerning the most appropriate planting practices, Li et al. (2003) discussed some technical options (direct seeding, seed pelletization and transplanting) for the nickel-hyperaccumulator Alyssum murale; they concluded that direct seeding is the best solution/option. Again therefore, it is of interest to test the plants potentially suited for phytoremediation - hyperaccumulators and high biomass species - when subjected to the toxic elements during early stages of the growing cycle.

\section{Acknowledgements}

This trial was performed as part of a project granted by Italian Ministry of Education, University and Research in 1998-2000.

\section{References}

Baker A.J.M., McGrath S.P., Reeves R.D., Smith J.A.C. 2000. Metal hyperaccumulator plants: a review of the ecology and physiology of a biochemical resource for phytoremediation of metal-polluted soils. In: Terry N. et al. (eds.): Phytoremediation of contaminated soil and water: 85-107. Lewis Publishers, Boca Raton, Florida.
Brown S.L. Chaney R.L., Angle J.S., Baker A.J.M. 1995. Zinc and cadmium uptake by hyperaccumulator Thlaspi caerulescens grown in nutrient solution. Soil Sci. Soc. Am. J. 59, 125-133.

Clemens S., Palmgren M.G., Krämer U. 2002. A long way ahead: understanding and engineering plant metal accumulation. Trends Plant Sci. 7:309-315.

Dushenkov S., Vasudev D.D., Kapulnik Y., Gleba D., Fleisher D., Ting K.C., Ensley B. 1997. Removal of uranium from water using terrestrial plants. Environ. Sci. Tech. 31:3468-3474.

Ebbs S.D., Kochian L.V. 1998. Phytoextraction of zinc by oat (Avena sativa), barley (Hordeum vulgare) and Indian mustard (Brassica juncea). Environ. Sci. Technol. 32:802-806.

Hammer D., Keller C. 2002. Changes in the rhizosphere of metal-accumulating plants evidenced by chemical extractants. J. Environ. Qual. 31:1561-1569.

Jiang X.J., Luom Y.M., Zhao Q.G., Baker A.J.M., Christie P., Wong H. 2003. Soil Cd availability to Indian mustard and environmental risk following EDTA addition to Cd-contaminated soil. Chemosphere, 50:813-818.

Kochian L.V., Pence N.S., Letham D.L.D., Pineros M.A., Magalhaes J.V., Hoekenga O.A., Garvin D.F. 2002. Mechanisms of metal resistance in plants: aluminum and heavy metals. Plant Soil 247:109-119.

Li Y.M., Chaney R., Brewer E., Roseberg R., Angle J.S., Baker A.J.M., Reeves R., Nelkin J. 2003. Development of a technology for commercial phytoextraction of nickel: economic and technical considerations. Plant Soil 249:107-115.

Mattina M.J.I., Lannucci-Berger W., Musante C., White J.C. 2003. Concurrent plant uptake of heavy metals and persistent organic pollutants from soil. Environ. Pollut. 124:375-378.

Mei B., Puryear J.D., Newton R.J. 2002. Assessment of $\mathrm{Cr}$ tolerance and accumulation in selected plants species. Plant Soil 247:223-231.

Mulligan C.N., Young R.N., Gibbs B.F. 2001. Remediation technologies for metal-contaminated soils and groundwater: an evolution. Eng. Geol. 60:193-207.

Salt D.E., Pickering I.J., Prince R.C., Gleba D., Dushenkov S., Smith R.D., Raskin I. 1997. Metal accumulation by aquacultured seedlings of Indian Mustard. Environ. Sci. Technol. 31:1636-1644.

Shahandeh H., Hossner L.R. 2000a. Plant screening for chromium phytoremediation. Int. J. Phytor. 2:31-51.

Shahandeh H., Hossner L.R. 2000b. Enhancement of Cr(III) phytoremediation. Int. J. Phytor. 2:269-286.

US EPA Method 3051 1994. Microwave-Assisted Acid Digestion of Sediments, Sludges, Soils and Oils. Washington DC, USA.

Zhao F.L., Lombi E., McGrath S.P. 2003. Assessing the potential for zinc and cadmium phytoremediation with the hyperaccumulator Thlaspi caerulescens. Plant Soil 249:37-43. 